\title{
Change in the dimensions of the lumbar area muscles after surgery: MRI analysis
}

\author{
(D) Fatma Duman, ${ }^{1}$ (D) Yurdal Serarslan, ${ }^{2}$ (D) Fatma Ozturk, ${ }^{3}$ (D) Bircan Yucekaya, ${ }^{4}$ (D) Nesrin Atci ${ }^{3}$ \\ ${ }^{1}$ Department of Anatomy, Mustafa Kemal University Faculty of Medicine, Hatay, Turkey \\ 2Department of Neurosurgery, Mustafa Kemal University Faculty of Medicine, Hatay, Turkey \\ ${ }^{3}$ Department of Radiology, Mustafa Kemal University Faculty of Medicine, Hatay, Turkey \\ ${ }^{4}$ Department of Physiotherapy and Rehabilitation, Mustafa Kemal University Faculty of Medicine, Hatay, Turkey
}

\begin{abstract}
OBJECTIVE: This study aims to assess the change in the dimensions of the lumbar muscles in patients with chronic lower back pain using Magnetic Resonance Imaging (MRI) and to determine pre/post effects of surgery.

METHODS: We enrolled 28 individuals (13F/15M; age: 45.39 \pm 11.56 years) whose L2-S1 muscle measurements were obtained using MRI, before and at follow-up 6-12 months after surgery. The control group comprising 37 individuals (18F/19M; age: $34.41 \pm 10.72$ years) who had no lumbar pathology but for whom retrospective archive images were available. In the axial MRI analysis, the cross-sections of m.multifidus, mm.erector spinae and m.psoas major on both sides were measured with the 'closed polygon' technique.
\end{abstract}

RESULTS: The $L 2-3$ and $L 4-5$ levels of the m.multifidus on the right side, the $L 2-3, L 4-5$ and $L 5-S 1$ levels of the m.multifidus and the L5-S1 levels of the $\mathrm{mm}$. erector spinae on the left side cross-sectional areas were significantly lower than the control group $(p<0.05)$. The right-side m.multifidus and the left-side mm.erector spinae sectional areas were significantly lower than the pre-surgery values at the L5-S1 levels $(p<0.05)$.

CONCLUSION: This study demonstrated that chronic lower back pain causes atrophy in the lumbar muscles and established the existence and continuity of atrophy after surgery.

Keywords: Lumbar surgery; MRI; muscle atrophy.

Cite this article as: Duman F, Serarslan Y, Ozturk F, Yucekaya B, Atci N. Change in the dimensions of the lumbar area muscles after surgery: MRI analysis. North Clin Istanb 2020;7(5):478-486.

C hronic lower back pain is a critical health-related problem, with over $70 \%$ lifetime prevalence reported in industrialised counties [1]. While $80 \%$ of patients with acute lower back pain recover within six weeks, the pain lasts for more than three months in approximately $7 \%-10 \%$ of patients, thereby adversely affecting work performance and the economy [2]. Besides the loss in muscle power associated with long-term inactivation and inadequacies in voluntary neural activation, atrophy of type two muscle fibres and changes in connective tis- sues are observed in patients with lower back pain. These changes could be attributed to the non-use and reflex inhibition that result in strength loss in muscles and muscle groups [3].

Notwithstanding the primary pathology, other components of the spinal motion segment are also affected in patients with chronic lower back pain [4]. Reportedly, leading changes are in the dimensions and symmetry of the paraspinal muscles, which play a vital role in facilitating movements and the formation of posture [5]. Some stud-

Received: January 06, 2020 Accepted: April 20, 2020 Online: August 18, 2020

Correspondence: Fatma DUMAN, MD. Mustafa Kemal Universitesi Tip Fakultesi, Anatomi Anabilim Dali, Hatay, Turkey.

Tel: +90 3262455114 e-mail: fatmaoz22@hotmail.com

(c) Copyright 2020 by Istanbul Provincial Directorate of Health - Available online at www.northclinist.com 
ies have reported atrophy in these muscles after lumbar area operations that negatively affect the life quality of the patients and decreases post-operative satisfaction $[6,7]$.

Regarding post-operative atrophy, some studies suggest that it is a result of iatrogenic denervation or ischaemic or thermal damage [8-10]. Moreover, this condition has been proven to increase morbidity besides pain and instability [11]. Some other studies have considered the affection of the posterior branches of spinal nerves to be the reason for atrophy, and it is reported that the damage does not remain intersegmental only but causes a potential risk regarding innervation $[11,12]$.

This study aims to investigate the changes in the dimensions of lumbar area muscles ( $\mathrm{m}$. psoas major, $\mathrm{m}$. multifidus and $\mathrm{mm}$. erector spinae) in patients with chronic lower back pain through magnetic resonance imaging (MRI) and to compare these results with measurements taken for healthy individuals, to elucidate the relationship between the dimensions of these muscles before and after surgery. In addition, another aim was to determine the changes in patients' daily life activities (DLA), capacity loss and satisfaction levels after surgery.

\section{MATERIALS AND METHODS}

\section{Patients}

This study was conducted by members of the Mustafa Kemal University, Department of Anatomy, Physiotherapy and Rehabilitation College and the Department of Neurosurgery and Radiology, with the approval of the Clinical Research Ethics Committee (no: 4298783/05023). We obtained written, informed consent from all participants in this study.

The study group comprised 28 individuals (13 females and 15 males) who underwent a lumbar microdiscectomy in patients with lumbar disc herniation. We obtained the morphometric measurements of the lumbar area muscles at the L2-S1 level through the routine MRI performed for normal follow-up before surgery and at 6-12 months after surgery [13]. The control group comprised 37 individuals (18 females and 19 males) for whom retrospective archive images were available. These individuals had attended our hospital for a consultation about lower back pain complaints but did not present any pathology in the radiological analyses.

We examined the members of the study group, obtained their demographic information and performed clinical examinations. Then, the effects of lower back complaints on their daily lives and pain levels before and after surgery were queried using the Modified Functional Ability Evaluation Form [2]. In addition, their satisfaction concerning their surgeries was evaluated with the Prolo Satisfaction Scale. This scale was comprised of two sub-groups: the economic part reflects each patient's work capacity, and the functional part reflects the impact on each patient's daily activities $[14,15]$. In addition, we asked participants whether they had physiotherapy and rehabilitation before and after surgery. From patients who had physiotherapy and rehabilitation, data about the treatment method (home-based programme/PR unit) and duration were also included in the evaluation.

\section{Surgical Procedure}

Under the general anaesthesia, the patients were placed in the prone position and after identifying the correct level with A C-arm scopy, a midline small skin incision was made. The dorsolumbar fascia was incised with a scalpel. The paraspinal muscles were exposed and dissected subperiosteally from the spinous processes and lamina using a periosteal elevator pressed against the edge of the spinous process on the ipsilateral side. The lateral border of the dissection is the medial facet joint. A hemilaminectomy retractor was placed. Under a surgical microscope, a laminotomy, flavectomy, microdiscectomy and foraminotomy were performed on the herniated disc level.

\section{MRI Protocol and Measurements}

In this study, MRI was performed on all participants with the 1.5 Tesla MR Device (Philips Achieva, Best, the Netherlands), using the 'Spain 15 ' coil. In addition, the sagittal and axial T2A turbo-spin echo (TSE) sequences were evaluated retrospectively. The sagittal T2A TSE sequence protocol was as follows: TR/TE, 3000/120; TSE, 3; matrix: 252x320; field of view (FOV), 250 and section thickness, $4 \mathrm{~mm}$. The axial T2A TSE sequence protocol was as follows: TR/TE, 4000/120; TSE, 3; matrix: 252x147; FOV, 200 and section thickness, $4 \mathrm{~mm}$.

We assessed the lumbar MRI measurements of the patients with the DICOM viewer programme (OsiriX, Pixmeo Labs, Geneva, Switzerland). In the axial lumbar MRI analysis, the cross-sections of $\mathrm{m}$. multifidus, $\mathrm{mm}$. erector spinae and $\mathrm{m}$. psoas major on both sides of the L2-3, L3-4, L4-5 and L5-S1 intervertebral disc distance levels were evaluated using the existing software (Fig. 1-3). All measurements were made from the section passing through the midpoint of the intervertebral 


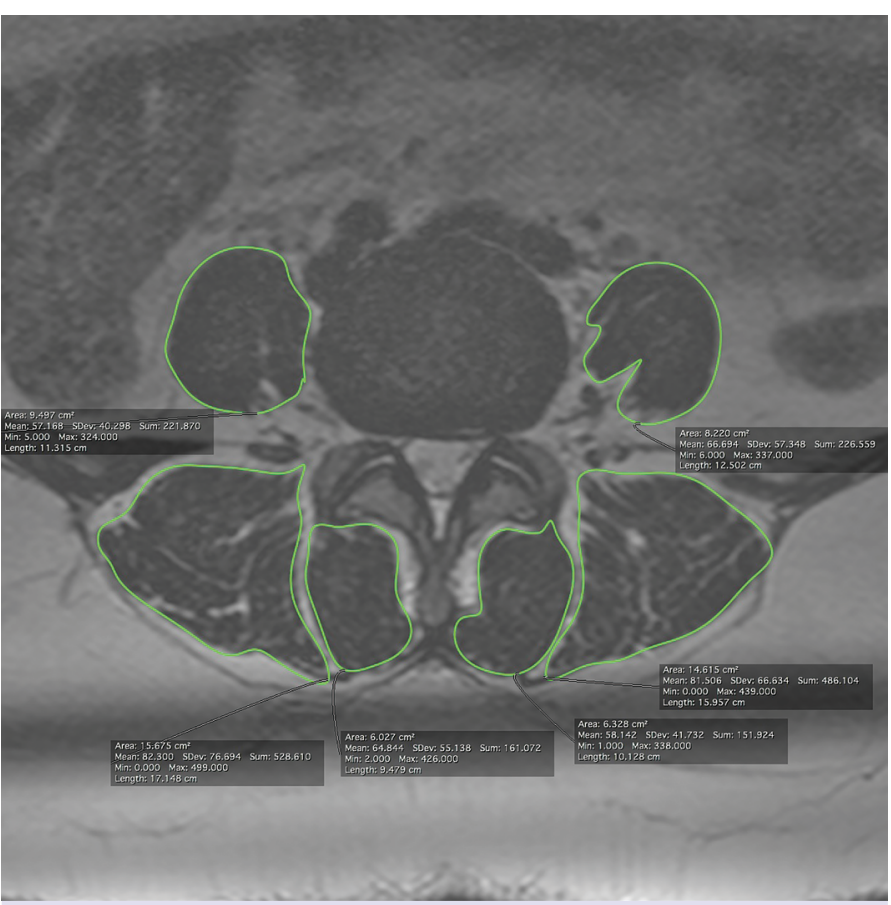

FIGURE 1. Through the axial T2A TSE images, which pass through different levels in the control group, the morphometric analysis of $\mathrm{mm}$. erector spinae $(A)$, m. multifidus $(B)$ and $\mathrm{m}$. psoas major (C).

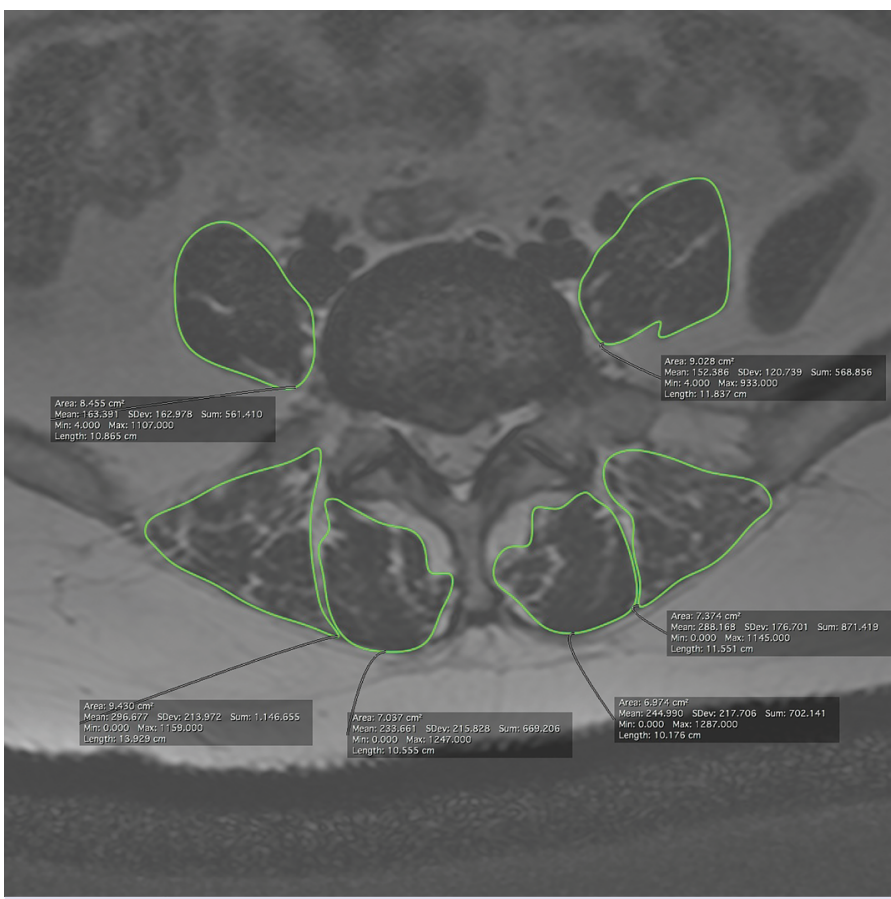

FIGURE 2. Through the axial T2A TSE images, which pass through different levels in the study group in the pre-operative period, the morphometric analysis of $\mathrm{mm}$. erector spinae (A), m. multifidus (B) and $m$. psoas major (C).

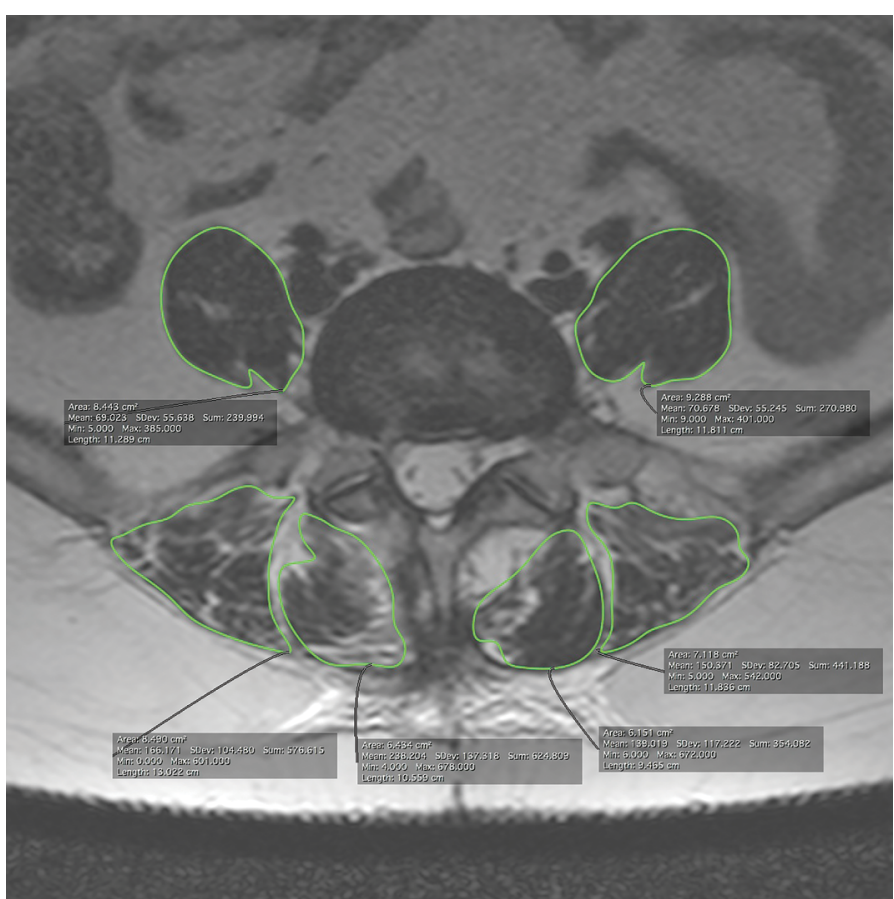

FIGURE 3. Through the axial T2A TSE images, which pass through different levels in the study group in the post-operative period, the morphometric analysis of $\mathrm{mm}$. erector spinae (A), m. multifidus (B) and $m$. psoas major (C).

TABLE 1. Distribution of the demographic characteristics according to group

$\begin{array}{cc}\text { Study } & \text { Control } \\ \% & \%\end{array}$

\section{Gender}

$\begin{array}{ccc}\text { Female } & 46.4 & 48.6 \\ \text { Male } & 53.6 & 51.4 \\ \text { tal } & 100.0 & 100.0\end{array}$

Has had PR?

Yes

No

28.6

71.4

Total

100.0

Treatment manner

Home programme

PR unit

75.0

Total

25.0

100.0

Age, Mean \pm SD

$45.39 \pm 11.558$

$34.41 \pm 10.717$

(Min.-Max.)

(24-70)

(19-57)

PR: Physiotherapy and rehabilitation; SD: Standard deviation. 
disc level. The measurements of the cross-sectional area were measured by manually constructing polygon points around the outer margins of the individual muscles [16].

\section{Statistical Analysis}

$\mathrm{G}^{\star}$ Power package software program $\left(\mathrm{G}^{\star}\right.$ Power, Version 3.1.9.4, Franz Faul, Universität Kiel, Germany) was used to calculate the required sample size for this study. According to the multifidus muscle's area measurements $\left(\mathrm{cm}^{2}\right)$ in sections that traversed the level of the L4 upper endplate, it was calculated that a sample consisting of 46 subjects ( 23 per group) was needed to obtain $80 \%$ power with $\mathrm{d}=0.74$ effect size, $\alpha=0.05$ type I error, and $\beta=0.20$ type II error. Due to an expected dropout rate of $20 \%$, we planned to recruit at least 56 patients ( 28 per group) for this study [17].

The data were analysed using the IBM SPSS Statistics 22 programme. We used frequency distributions for categorical variables and descriptive statistics for numerical variables (mean \pm standard deviation $[S D]$ ). Since the normalcy assumption was supported by the preceding test, we proceeded to analyse the data with parametrical tests. In addition, we assessed the difference between the two dependent groups (comparison of lumbar area muscle dimensions before and after surgery) with the Dependent Sampling T-Test and the two independent groups (comparison of lumbar area muscle dimensions before surgery with those for the control group) with the Independent Sampling T-Test, respectively. Furthermore, we used the Pearson Correlation Coefficient to determine the degree of correlation between the functional ability of daily life activities and satisfaction concerning their surgeries.

\section{RESULTS}

In the study group, $46.4 \%$ of 28 individuals were females (median age $45.39 \pm 11.56$ years) and $53.6 \%$ were males. In contrast, in the control group, $48.6 \%$ of participants were females and $51.4 \%$ were males (median age: $34.41 \pm 10.72$ years; Table 1 ).

Of note, a majority of participants who had surgery were housewives. In addition, $28.6 \%$ of participants had physiotherapy; of these, only two participants were treated at the PR unit and the remaining participants were followed-up through a home-based programme (Table 1).

Regarding measurements taken before surgery through MRI, a comparison between the study and control groups' lumbar area muscle dimensions revealed significant differences between the two groups $(p<0.05)$. In the study group and on the right side, the segment areas of $m$. multifidus at the $L 2-3(p=0.017)$ and L4-5 $(p=0.042)$ levels were significantly lower than those of the control group. On the left side, the segment areas of $\mathrm{m}$. multifidus at the L2-3 ( $\mathrm{p}=0.034)$, L4-5 ( $\mathrm{p}=0.14)$ and L5-S1 $(\mathrm{p}=0.027)$ levels and the segment areas of $\mathrm{mm}$. erector spinae at the L5-S1 $(p=0.038)$ levels were significantly lower than those of the control group (Table 2).

A comparison of the measurements of the lumbar area muscle dimensions before and after surgery revealed significant differences between the two groups $(\mathrm{p}<0.05)$. It was determined that the right-side $\mathrm{m}$. multifidus $(p=0.038)$ and the left-side $\mathrm{mm}$. erector spinae $(p=0.031)$ segment areas after surgery were significantly smaller at the L5-S1 levels compared to those before surgery (Table 3 ).

The Modified Oswestry score after surgery displayed a positive decline $(p=0.000$; Table 4$)$. Furthermore, we observed a negative medium-level significant and direct correlation between the Modified Oswestry total score and Prolo Satisfaction economic $(r=-0.479 ; \mathrm{p}=0.010)$ and functional $(r=-0.569 ; p=0.002)$ scores of the individuals after surgery (Table 5 ).

\section{DISCUSSION}

Although several trunk muscles play a role in the control and stability of the spine, the paraspinal muscles are critical in the segmental stabilisation of the spine. Of the lumbar area pathologies and at all of their phases, whether acute or chronic, the structural and functional changes of the paraspinal muscles of this area are always significant [5]. Studies have demonstrated atrophy in the lumbar area muscles and the increase of fat tissues in patients with lumbar area pathologies [18-21].

In this study, the segment areas of $m$. multifidus, $m$. psoas major and $\mathrm{mm}$. erector spinae in individuals who underwent lumbar microdiscectomy surgery throughout the L2-S1 levels were measured. A comparison of the muscles' lengths of the surgery group and the control group revealed that the average segment area of individuals who had surgery was significantly lower than that of the control group $(p<0.05)$. On the right side, $m$. multifidus at the L2-3 $(\mathrm{p}<0.0179)$ and L4-5 $(\mathrm{p}<0.042)$ levels and, on the left side, m. multifidus at the L2-3 
TABLE 2. Comparison of the lumbar area muscle dimensions before surgery with those for the control group

\begin{tabular}{|c|c|c|c|c|c|c|}
\hline \multirow[t]{2}{*}{ Before surgery } & \multicolumn{2}{|c|}{ Study $(\mathrm{N}=28)$} & \multicolumn{2}{|c|}{ Control $(\mathrm{N}=37)$} & \multirow[t]{2}{*}{$\mathrm{t}$} & \multirow[t]{2}{*}{$\mathrm{p}$} \\
\hline & Mean & SD & Mean & SD & & \\
\hline \multicolumn{7}{|l|}{ Right } \\
\hline \multicolumn{7}{|l|}{ L2-L3 } \\
\hline M. multifidus & 3001.86 & 782.949 & 3641.73 & 1193.972 & -2.461 & $0.017 *$ \\
\hline Mm. erector spinae & $17,674.54$ & 4950.963 & $16,240.41$ & 4470.274 & 1.223 & 0.226 \\
\hline M. psoas major & 6352.79 & 3265.802 & 6109.11 & 3126.971 & 0.305 & 0.761 \\
\hline \multicolumn{7}{|l|}{ L3-L4 } \\
\hline M. multifidus & 4914.89 & 1443.369 & 5310.14 & 1342.866 & -1.138 & 0.260 \\
\hline Mm. erector spinae & $16,042.25$ & 4748.016 & $15,338.57$ & 4633.995 & 0.600 & 0.551 \\
\hline M. psoas major & 9976.04 & 4081.503 & 9256.54 & 3879.356 & 0.724 & 0.472 \\
\hline \multicolumn{7}{|l|}{ L4-L5 } \\
\hline M. multifidus & 6445.14 & 1830.549 & 7266.49 & 1359.678 & -2.077 & $0.042 *$ \\
\hline Mm. erector spinae & $11,588.54$ & 2697.908 & $12,426.14$ & 3410.18 & -1.070 & 0.289 \\
\hline M. psoas major & $11,921.07$ & 4860.716 & $11,958.11$ & 4404.672 & -0.032 & 0.974 \\
\hline \multicolumn{7}{|l|}{ L5-S1 } \\
\hline M. multifidus & 7274.43 & 2826.568 & 8325.95 & 1545.567 & -1.918 & 0.060 \\
\hline Mm. erector spinae & 5364.89 & 2232.086 & 6604.76 & 3854.717 & -1.518 & 0.134 \\
\hline M. psoas major & 9666.07 & 3984.139 & $10,867.19$ & 4862.893 & -1.064 & 0.291 \\
\hline \multicolumn{7}{|l|}{ Left } \\
\hline \multicolumn{7}{|l|}{ L2-L3 } \\
\hline M. multifidus & 3123.18 & 1124.038 & 4342.81 & 2801.054 & -2.172 & $0.034 *$ \\
\hline Mm. erector spinae & $17,968.93$ & 4867.261 & $15,925.35$ & 5429.253 & 1.570 & 0.121 \\
\hline M. psoas major & 6229.71 & 3159.936 & 6197.19 & 3271.376 & 0.040 & 0.968 \\
\hline \multicolumn{7}{|l|}{ L3-L4 } \\
\hline M. multifidus & 5002.25 & 1514.353 & 5843.59 & 2912.448 & -1.391 & 0.169 \\
\hline Mm. erector spinae & $15,986.64$ & $39,72.149$ & $14,958.27$ & 4906.366 & 0.906 & 0.368 \\
\hline M. psoas major & 9508.36 & 4085.307 & 9502.7 & 3883.043 & 0.006 & 0.995 \\
\hline \multicolumn{7}{|l|}{ L4-L5 } \\
\hline M. multifidus & 6310.36 & 1530.957 & 7619.78 & 2378.428 & -2.540 & $0.014 *$ \\
\hline Mm. erector spinae & $11,080.64$ & 3256.125 & $11,811.46$ & 3590.711 & -0.845 & 0.401 \\
\hline M. psoas major & $11,640.00$ & 4709.539 & $11,801.97$ & 4357.381 & -0.143 & 0.886 \\
\hline \multicolumn{7}{|l|}{$\mathrm{L} 5-\mathrm{S} 1$} \\
\hline M. multifidus & 6723.82 & 2378.736 & 8213.38 & 2804.441 & -2.261 & $0.027 *$ \\
\hline Mm. erector spinae & 4878.32 & 2487.575 & 6450.73 & 3275.489 & -2.118 & $0.038 *$ \\
\hline M. psoas major & 9475.36 & 4264.56 & $10,586.86$ & 4429.952 & -1.018 & 0.313 \\
\hline
\end{tabular}

SD: Standard deviation; Independent Sample T-Test; ${ }^{*}$ p $<0.05$; L: Lumbar; S: Sacral (measurements are of the mm² type).

$(\mathrm{p}=0.034), \mathrm{L} 4-5(\mathrm{p}=0.014)$ and L5-S1 $(\mathrm{p}<0.027)$ levels and $\mathrm{mm}$. erector spinae at the L5-S1 $(\mathrm{p}=0.034)$ levels were found to be atrophic.

Lumbar surgeries aim to decompress neurological structures and achieve the integrity of the spine. Although differences are observed for surgical techniques, the manipulation of the paraspinal muscles is inevitable, which makes these muscles prone to the atrophy after surgery. Some studies have underlined that muscle damage after surgery is significantly related to long-term muscle atrophy and fat infiltration $[11,22]$. This study demonstrated that the atrophy of the lumbar area mus- 
TABLE 3. Analysis of the difference between lumbar area muscle dimensions before and after surgery

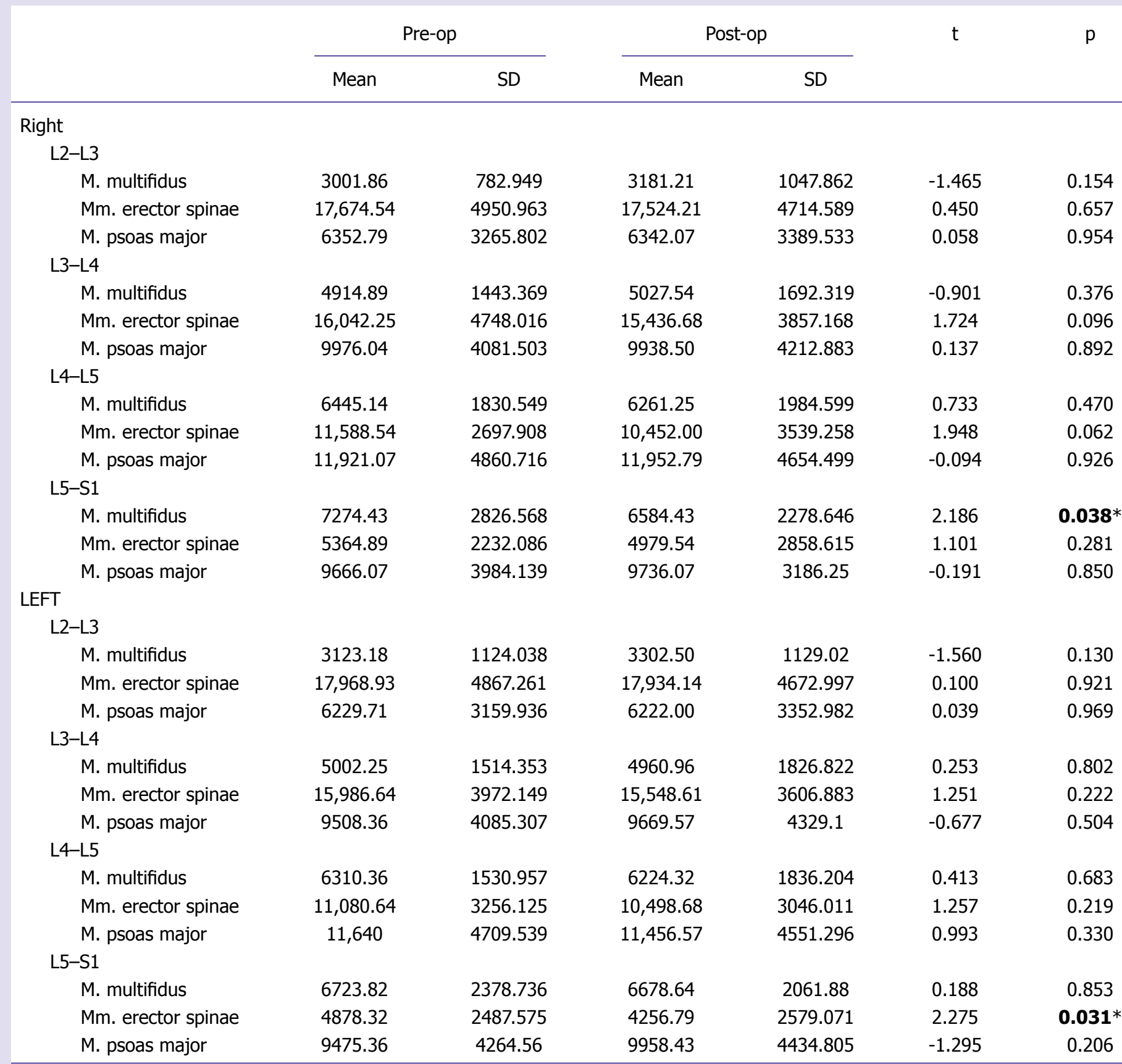

SD: Standard deviation; Dependent Sample T-Test; *: p<0.05; L: Lumbar; S: Sacral (measurements are of the $\mathrm{mm}^{2}$ type).

cles in the post-operative period gradually increased. In addition, a comparison of MRI images before and after surgery revealed that $m$. multifidus $(p=0.038)$ on the right side and $\mathrm{mm}$. erector spinae $(\mathrm{p}<0.031)$ on the left side were significantly atrophied at the L5-S1 levels after surgery.
Suwa et al. [21] reported that an average of 30-min muscle retraction was experienced by 42 patients who underwent a one-level interlaminar laminectomy procedure. On the $10^{\text {th }}$ and $12^{\text {th }}$ pre-op and post-op months, the researchers evaluated the thickness of the paraspinal muscles with the anteroposterior 'CT slice parallel' 
TABLE 4. Analysis of the relationship between the Modified Oswestry Scale scores before and after surgery

\begin{tabular}{|c|c|c|c|c|c|c|c|}
\hline & \multirow[t]{2}{*}{$\mathrm{N}$} & \multicolumn{2}{|c|}{ Pre-op } & \multicolumn{2}{|c|}{ Post-op } & \multirow[t]{2}{*}{$\mathrm{t}$} & \multirow[t]{2}{*}{$\mathrm{p}$} \\
\hline & & Mean & SD & Mean & SD & & \\
\hline Modified Oswestry Scale Total Score & 28 & 54.50 & 7.244 & 21.46 & 7.105 & 21.345 & $0.000 *$ \\
\hline
\end{tabular}

SD: Standard deviation; Dependent Sample T-Test; *: p<0.001.

TABLE 5. Analysis of the relationship between the Prolo Satisfaction Scale scores and Modified Oswestry Scale after surgery

\begin{tabular}{lccc} 
& N & r & p \\
\hline Oswestry Total Score* Economic Prolo Score & 28 & -0.479 & $\mathbf{0 . 0 1 0}^{*}$ \\
Oswestry Total Score* Functional Prolo Score & 28 & -0.569 & $\mathbf{0 . 0 0 2}^{* *}$ \\
\hline
\end{tabular}

Pearson Correlation; *: $\mathrm{p}<0.05 ; * *: \mathrm{p}<0.01$.

method and reported atrophy at the end of 12 months [23]. Gejo et al. [24] reported that post-op trunk muscle strength was related to muscle retraction time and operation time.

Hartwig et al. [25] reported an increase in the atrophy of and the fat amount in the volume of the paravertebral muscles, through three-dimensional analysis of the lumbar paravertebral muscle measurements obtained in the $1^{\text {st }}$ and $12^{\text {th }}$ post-op months for 20 patients who had undergone a single level (L4-5) fusion. In another study in which three different decompressive surgery techniques were compared, the atrophy amount of the more invasive method was statistically higher than that of the other methods, and the average $\mathrm{C}$-reactive protein and haemoglobin amounts varied as well [6]. For laterality, the literature has shown that there is no significant difference in right or left side [26,27]. In this study, there were no statistically differences between sides, but different muscle atrophies were observed on the several vertebral level. Considering that the surgical method is the same in all cases for the right and left side, these differences can be explained as: negative postural changes with muscle strength weakness in the preoperative period, time period between disease and surgery, and presence of inactivity in daily life. We believe that these parameters should be evaluated clearly in future studies. However, we should note that these studies provided no information regarding whether exercise, a leading factor that might prevent muscle atrophy, was performed before the surgeries and during the recovery periods. Hence, the lack of information about physiotherapy protocol modalities and durations is a disadvantage of these studies.

In this study, only $28.6 \%(\mathrm{~N}=8)$ of the participants had PR after surgery. While only two of these participants were followed-up in the PR unit, the remaining participants were followed-up with a home-based programme. All of these participants denied performing any exercise at home. In addition, it was observed that individuals limited even their simple DLA and household chores to avoid the pain that they had before surgery and to not risk requiring another operation. Hence, inactivity also plays a role in the formation of atrophy. However, it is underlined in the literature that exercise positively affects the lumbar area muscles [19]. Furthermore, Gildea et al. [28] reported a positive development in the lumbar muscles sectional area after individuals started exercising again after surgery.

The assessment of the loss of function ability to perform daily activities and the life quality of participants with the Modified Oswestry Scale determined that the pain experienced by individuals was significantly lower, and there was a significant increase in their functionality during daily life after surgery. Besides this positive development, it was also observed that individuals' economic and functional satisfaction increased [14]. Consistent with the literature, we observed a negative medium-level 
significant and direct correlation between the Modified Oswestry total score and Prolo Satisfaction economic and functional scores of the individuals after surgery (Table 5).

This study has several limitations. This study had a limited sample size and muscle quality and fatty degeneration could not be evaluated. The measurement technique we used only gave a gross measurement of muscle CSA and we did not measure the total volume of each muscle. Volume outcomes will be important to show atrophy clearly.

In conclusion, this study demonstrates that chronic lower back pain hinders the daily life of people experiencing this pain and causes atrophy in the lumbar area muscles of these individuals. In addition, this study established the existence and continuity of atrophy in people who had undergone lumbar area surgery, whereas clinical findings are getting better. Thus, further studies investigating etiological factors and effective factors during surgery (surgery duration, the surgery type and muscle retraction) are warranted to investigate how to prevent or minimise atrophy for patients undergoing this form of surgery. Overall, it is suggested that the effects of inactivity on atrophy should not be ignored, and the efficiency of different exercise programmes to be suggested to individuals in the post-op period should be studied.

Informed Consent: We obtained written, informed consent from all participants in this study.

Ethics Committee Approval: This study was conducted by members of the Mustafa Kemal University Department of Anatomy, Physiotherapy and Rehabilitation College and the Department of Neurosurgery and Radiology, with the approval of the Clinical Research Ethics Committee (date: 22.10.2015, number: 06).

Conflict of Interest: No conflict of interest was declared by the authors.

Financial Disclosure: The authors declared that this study has received no financial support.

Authorship Contributions: Concept - FD, FO, YS; Design - FD, FO, YS, BY, NA; Supervision - FD, FO, YS, BY, NA; Fundings - FD, $\mathrm{BY}$; Materials - FD, YS; Data collection and/or processing - FD, FO, NA; Analysis and/or interpretation - FD, FO, YS, BY, NA; Literature review - FD, FO, YS, BY; Writing - FD, FO, YS, BY; Critical review $F D, F O, Y S, B Y, N A$.

\section{REFERENCES}

1. Loney PL, Stratford PW. The prevalence of low back pain in adults: a methodological review of the literature. Phys Ther 1999;79:384-96.

2. Suyabatmaz Ö, Çağlar NS, Tütün Ş, Özgönenel L, Burnaz Ö, Aytekin E, et al. Assessment of the Effect of Back School Therapy in Patients with Low Back Pain. Istanbul Med J 2011;12:5-10. [CrossRef]
3. Lehto $M$, Hurme $M$, Alaranta $H$, Einola $S$, Falck $B$, Järvinen $M$, et al. Connective tissue changes of the multifidus muscle in patients with lumbar disc herniation. An immunohistologic study of collagen types I and III and fibronectin. Spine (Phila Pa 1976) 1989;14:302-9. [CrossRef]

4. Şahin N, Özcan E. Demographic Features and Functional Status in Patients With Failed Back Surgery Syndrome. Selçuk Tip Derg 2012;28:219-21.

5. Hides J, Gilmore C, Stanton W, Bohlscheid E. Multifidus size and symmetry among chronic LBP and healthy asymptomatic subjects. Man Ther 2008;13:43-9. [CrossRef]

6. Kim K, Isu T, Sugawara A, Matsumoto R, Isobe M. Comparison of the effect of 3 different approaches to the lumbar spinal canal on postoperative paraspinal muscle damage. Surg Neurol 2008;69:109-13. [CrossRef]

7. Shahidi B, Hubbard JC, Gibbons MC, Ruoss S, Zlomislic V, Allen RT, Garfin SR, Ward SR. Lumbar multifidus muscle degenerates in individuals with chronic degenerative lumbar spine pathology. J Orthop Res. 2017;35:2700-6. [CrossRef]

8. Kim DY, Lee SH, Chung SK, Lee HY. Comparison of multifidus muscle atrophy and trunk extension muscle strength: percutaneous versus open pedicle screw fixation. Spine (Phila Pa 1976) 2005;30:123-9.

9. Styf JR, Willén J. The effects of external compression by three different retractors on pressure in the erector spine muscles during and after posterior lumbar spine surgery in humans. Spine (Phila Pa 1976) 1998;23:354-8. [CrossRef]

10. Motosuneya T, Asazuma T, Tsuji T, Watanabe H, Nakayama Y, Nemoto K. Postoperative change of the cross-sectional area of back musculature after 5 surgical procedures as assessed by magnetic resonance imaging. J Spinal Disord Tech 2006;19:318-22. [CrossRef]

11. Pourtaheri S, Issa K, Lord E, Ajiboye R, Drysch A, Hwang K, Faloon M, Sinha K, Emami A. Paraspinal Muscle Atrophy After Lumbar Spine Surgery. Orthopedics 2016;39:e209-14. [CrossRef]

12. Bogduk N, Wilson AS, Tynan W. The human lumbar dorsal rami. J Anat 1982;134:383-97.

13. Lee CS, Kang KC, Chung SS, Park WH, Shin WJ, Seo YG. How does back muscle strength change after posterior lumbar interbody fusion?. J Neurosurg Spine 2017;26:163-70. [CrossRef]

14. Vanti C, Prosperi D, Boschi M. The Prolo Scale: history, evolution and psychometric properties.J Orthop Traumatol 2013;14:235-45. [CrossRef]

15. Mumcu C, Gök H, Gülec I, Naderi S. Effectiveness of Selective Transforaminal Nerve Root Block in Recurrent Lumbar Disc Herniations. Türk Nöroşirürji Dergisi 2012;22:1-6.

16. Sasaki T, Yoshimura N, Hashizume H, Yamada H, Oka H, Matsudaira $\mathrm{K}$, et al. MRI-defined paraspinal muscle morphology in Japanese population: The Wakayama Spine Study. PLoS One 2017;12:e0187765.

17. Kamaz M, Kireşi D, Oğuz H, Emlik D, Levendoğlu F. CT measurement of trunk muscle areas in patients with chronic low back pain. $\mathrm{Di}$ agn Interv Radiol 2007;13:144-8.

18. Kim YE, Choi HW. Does stabilization of the degenerative lumbar spine itself produce multifidus atrophy?. Med Eng Phys 2017;49:63-70.

19. Takashima H, Takebayashi T, Ogon I, Yoshimoto M, Morita T, Imamura R, et al. Analysis of intra and extramyocellular lipids in the multifidus muscle in patients with chronic low back pain using MR spectroscopy. Br J Radiol 2018;91:20170536. [CrossRef]

20. Ashana AO, Ajiboye RM, Sheppard WL, Sharma A, Kay AB, Holly LT. Cervical Paraspinal Muscle Atrophy Rates Following Laminoplasty and Laminectomy with Fusion for Cervical Spondylotic Myelopathy. World Neurosurg 2017;107:445-50. [CrossRef]

21. Suwa H, Hanakita J, Ohshita N, Gotoh K, Matsuoka N, Morizane A. Postoperative changes in paraspinal muscle thickness after various lum- 
bar back surgery procedures. Neurol Med Chir (Tokyo) 2000;40:151-5.

22. Fan S, Hu Z, Zhao F, Zhao X, Huang Y, Fang X. Multifidus muscle changes and clinical effects of one-level posterior lumbar interbody fusion: minimally invasive procedure versus conventional open approach. Eur Spine J 2010;19:316-24. [CrossRef]

23. Lehto $M$, Hurme $M$, Alaranta $H$, Einola $S$, Falck B, Järvinen $M$, et al. Connective tissue changes of the multifidus muscle in patients with lumbar disc herniation. An immunohistologic study of collagen types I and III and fibronectin. Spine (Phila Pa 1976) 1989;14:302-9. [CrossRef]

24. Gejo R, Matsui H, Kawaguchi Y, Ishihara H, Tsuji H. Serial changes in trunk muscle performance after posterior lumbar surgery. Spine (Phila Pa 1976) 1999;24:1023-8. [CrossRef]
25. Hartwig T, Streitparth F, Gross C, Müller M, Perka C, Putzier M, et al. Digital 3-dimensional analysis of the paravertebral lumbar muscles after circumferential single-level fusion. J Spinal Disord Tech 2011;24:451-4. [CrossRef]

26. Lau D, Han SJ, Lee JG, Lu DC, Chou D. Minimally invasive compared to open microdiscectomy for lumbar disc herniation. J Clin Neurosci 2011;18:81-4. [CrossRef]

27. Barrett C, Cowie C, Mitchell P. Left sided lumbar disc prolapses are more common. Orthopaedic Proceedings 2012;94:082.

28. Gildea JE, Hides JA, Hodges PW. Size and symmetry of trunk muscles in ballet dancers with and without low back pain.J Orthop Sports Phys Ther 2013;43:525-33. [CrossRef] 